\title{
Illuminating homes with LEDs in India: Rapid market creation towards low-carbon technology transition in a developing country
}

\begin{abstract}
Near-term climate change mitigation calls for technological innovation and widespread implementation of appropriate technologies. This is salient in emerging economies, where impending socio-economic and infrastructural transitions hold immense potential for locking-in low-carbon development pathways. Yet, little is understood about how developing countries can scale appropriate technology transitions, given their often underdeveloped technological innovation capabilities and supporting infrastructures and finances. This paper examines a recent, rapid, and ongoing transition of India's lighting market to light emitting diode (LED) technology, from a negligible market share to LEDs becoming the dominant lighting products within five years, despite the country's otherwise limited visibility in the global solid-state lighting industry. Annual sales of LED bulbs grew more than 130 times to over 650 million bulbs between 2014-2018, with over 30 billion kWh of estimated annual energy savings. Focusing on this striking story of technology transition, this paper analyzes India's LED uptake, using semi-structured interviews and drawing on the technology innovation systems literature. The results show that the success of transition coexists with its share of shortfalls, and that there is an important tension between the lowering of upfront costs of low-carbon technologies and the efforts to enhance domestic technological capabilities. The paper discusses the results for the Indian LED case and emphasizes the importance of consistent strategic action taking into account all (and not limited) parts of the technology innovation system, while also providing insights on how mitigation technologies can be developed and deployed in developing countries.
\end{abstract}

Keywords: technology innovation systems; solid state lighting; light emitting diode (LED); India; climate change mitigation; developing countries; energy efficiency

\section{Introduction}


It is well established that to achieve the United Nations Framework Convention on Climate Change's (UNFCCC) goal to keep the rise in global temperatures below 2 degrees $\mathrm{C}$ requires technological innovation and widespread transfer and implementation of appropriate carbon mitigation technologies [1, 2]. Enabling such technological transitions is particularly salient in emerging economies, given their large-scale and ongoing development [1]. Further, with the changing spatial configuration of the world's economic activities, policy making and innovation research need to be ever more attentive to the progress made across countries [3, 4].

Yet, rapid diffusion of new low-carbon technologies is challenging for developing countries because of their relatively weaker technological and innovation capabilities and associated institutions, and the higher upfront technology costs $[1,5]$. As a result, these countries often initiate adoption of, or require catching-up with, a new technology when $R \& D$, design and development, market demonstration, and even commercialization may have already taken place in more developed countries. For the most part, the opportunities for technology transition have bypassed most emerging economies, with a few accounting for a large fraction of existing lowcarbon technology deployment, while others remain unattractive to foreign firms [6]. Also, while the UNFCCC discourse has been largely based on a North-South technology transfer paradigm, observations of technology and technology facilitation activities show an increasingly interconnected world, where many developing countries are actively absorbing foreign technologies while also developing and transferring technologies themselves [7].

A fundamental question therefore relates to whether developing countries have to content themselves with finding a position in existing global value chains or whether they will be able to lead new technological trajectories towards better economic and low-carbon development [8]. These are critical issues from policy-making and scholarly perspectives in climate mitigation and technology innovation research. The relevant literature that examines such processes, successes and missed opportunities in low-carbon technology value chains, however, remains thin [9].

This paper explores these issues by examining a recent case of exceptionally rapid, large-scale deployment of light emitting diode (LED) lighting (also referred to as 'solid-state lighting' or SSL) technology in India, where the market share of LED lamps (measured by the number of 
bulbs sold) grew from a third of a percent to $46 \%$ in five years. LED lighting took over incandescent bulbs as the dominant lighting technology in the country in this short period (Figure 1). To shed light on this unexpected shift in technology, this paper addresses two inter-related research questions: how and why did India make the rapid transition to LED lighting? In learning from the Indian experience, what are the key lessons for other low-carbon technological transitions in developing countries? As one of the first academic studies on the unprecedented LED lighting shift in India, this paper contributes to the limited knowledge base that explicitly puts forward approaches to examine if, and how, new technological trajectories can be created in emerging economy contexts $[8,10]$ [11-14]. Further, insights from this study are valuable for other developing regions with high growth and carbon emissions, juxtaposed with a low base of development, and where new and emerging climate-friendly technologies can be developed, deployed, and locked-in.

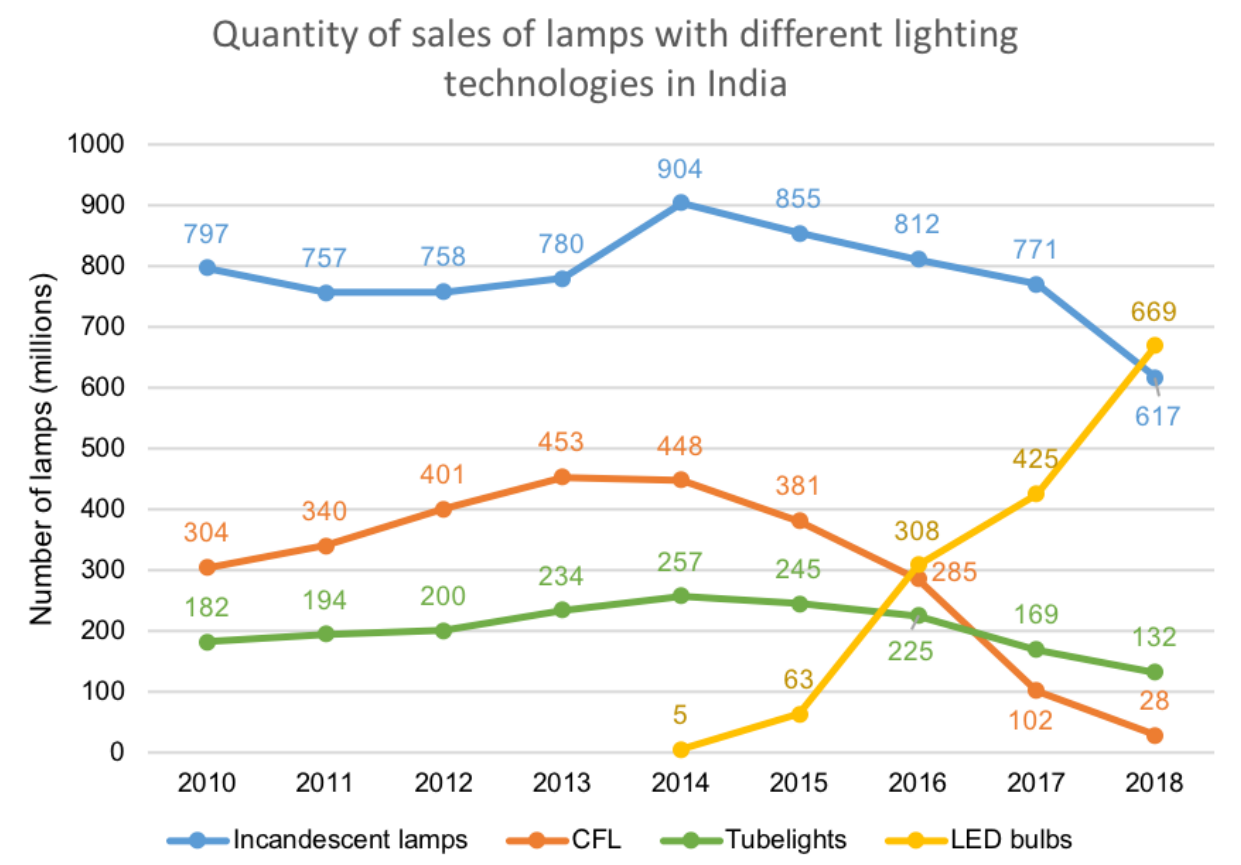

Figure 1: Lighting market trends in India (2010-2018). A 130-fold expansion of LED lighting market in India from 5 million LED bulbs sold in 2014 to 669 LED bulbs - more than incandescent bulbs - sold in 2018. Source: Lighting Industry Data in India 2010-2018 [15]. 
Such a case of rapid transition to an emerging technology is particularly interesting to study in the Indian context as the country's broader efforts to advance technology innovation capabilities have had mixed results. India's engagement with LED lamps manufacturing has been limited, which is instead dominated by China, from raw materials to manufacturing [16]. Companies from China, Taiwan, Japan, South Korea, USA, and Europe together account for $85 \%$ of global LED chip fabrication capacity [17, 18] (Figure 2(a)). India's relatively low rank in LED manufacturing is consistent with the country's lack of focus on being a major manufacturer or exporter of high-tech products (except for some success in automobiles and pharmaceuticals). While numerous government policies promote expansion of domestic high-tech manufacturing, the country spends $0.6 \%$ of its GDP on R\&D (in 2015), compared to the higher $2-4 \%$ spent by other countries (China at 2\%, South Korea at 4\%) [19]. In spite of this backdrop, India is now one of the largest global markets of LED lighting. This shift from a negligible base to about 10\% of the global market in three years between 2014-2016 (Figure 2(b)) demands an examination of the technological transition that is underway.

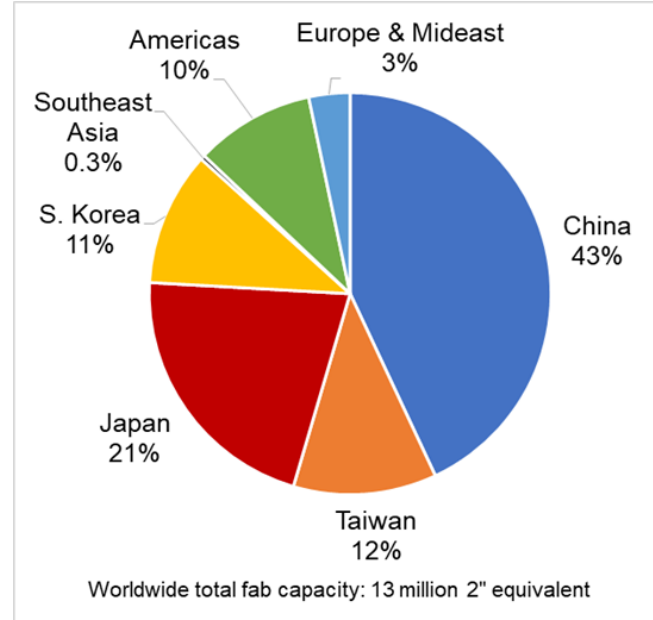

(a)

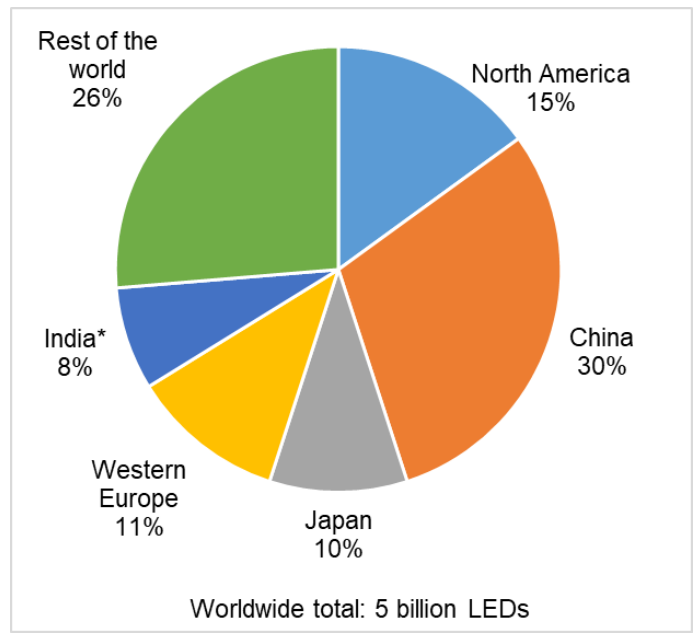

(b)

Figure 2: (a) Global LED epitaxy installed capacity in 2017 by country or region, measured by the number of 2" equivalent chips fabricated per month. In this figure, 'Southeast Asia' excludes Taiwan, Japan, and S. Korea. Source: SEMI, 2018 [18]. (b) Estimates of global LED market shares in 2016. *Market shares are based on the estimated number of installed LED lamps in North America, China, Japan, Western Europe, and 'Rest of the world' [17] and of sales of LED lamps in India [20]. 
It is important to place the LED transition in India within the broader context of lighting technology which has evolved from incandescent bulbs until the 1990s, to more efficient compact fluorescent lamps (CFLs) in the 2000s [34], and recently to LEDs which offer far lower energy use, double the usable life, and lower lifecycle costs $[17,21]$. The global price of LED lamps fell to $1 / 7^{\text {th }}$ of its price in 2010 [22] because of growing demand, high-volume processing technologies [17, 23, 24], standardization and commoditization of the LED chip technology, and increasing manufacturing capabilities of major exporters like China and Taiwan [25]. By 2015, high-efficiency LEDs represented $15 \%$ of the residential lamp sales worldwide [26]. However, further energy savings by a factor of a 100 are still possible with full adoption of LEDs in lighting and with resulting greenhouse gas emissions reduction, making it an important ongoing climate mitigation technological opportunity [22], especially as lighting accounts for $15 \%$ of global electricity consumption [17].

The paper is organized as follows. The next section lays out our methodological approach and draws from the innovation systems literature to propose a framework to examine and understand technology transitions in an emerging economy context. Section 3 describes the application of the framework to the upstream and downstream dimensions of the LED technology innovation chain in India. The following section discusses key insights from the empirical trends, successes, and missed opportunities from the Indian LED transition, and the final section provides broader insights on the direction of low-carbon innovation in developing economies.

\section{Methodological Approach}

Our methodological approach is twofold. First, building on the existing technology innovation systems literature, we propose a framework to investigate technological transitions in developing economies. Second, we apply this framework to India's LED lighting transition using empirical data from in-depth semi-structured interviews, data analysis, and an extensive assessment of the academic, industry, and policy literature. We discuss the theoretical framework and its rationale, followed up by a discussion of the empirical methods. 


\subsection{Theoretical framework}

Innovation systems thinking has guided research and innovation policy since the early 1990s. By departing from the then prevailing neo-classical thinking in economics, it recognized the essential, and inherently dynamic nature of innovation [27]. At the core of the innovation systems approach is the understanding that innovation requires a network of a wide range of actors who participate in the innovation process, through their individual activities and interactions, and who are embedded in an institutional landscape that shapes these activities and interactions and, in return, is shaped by them. These actors include industry, policy makers, higher education and research institutes, and non-profit organizations, among others. Innovation systems thinking captures the inherent complexity of innovation processes, which makes it particularly suitable to study technological transitions that involve early R\&D; design and development of products; market demonstration, commercialization, and formation; and diffusion - with non-linear interactions and feedbacks among each $[3,4]$.

Within this broader field, a prominent systemic framework is that of Technological Innovation Systems (TIS) [28-33]. The TIS perspective posits that innovation success is related to systemic interactions between a broad range of actors involved in the generation, diffusion, and utilization of a specific technology, along with a set of rules, norms and culture, formalized or informal coordination networks, and specific institutional structures which influence these processes [29, $30,34]$. We select the TIS approach to study transitioning technology-specific innovation systems in an emerging economy because, by definition, it attempts to capture innovation processes taking place in the context of a specific technology - in this case LED lighting. In addition, the TIS approach has two key advantages over other innovation systems frameworks. First, it is not limited to the boundaries of a single country, such as the approaches in the National Innovation Systems literature [35], or to the boundaries of a specific sector, as in the case of the Sectoral Innovation Systems literature [36]. Instead, a TIS-based approach can intersect multiple national and sectoral innovation systems [30]. This is important as the potential for sustainability and low-carbon transitions is increasingly governed by transnational

relationships and actors located at scales other than that of the nation state, such as multinational corporations, multi-lateral and bilateral donors, or non-governmental organizations, who may or 
may not reside in the places where transitions are desired or on-going [37]. Equally, the increasingly interactive and globalized nature of research and innovation activity, and international climate agreements and targets, demand an evolution of innovation systems thinking beyond the dominant national scale of analysis [27]. A further basis for using this approach is that the number of technology-specific actors, networks, and institutions is less than that in the entire national innovation system or a sectoral innovation system covering multiple technologies. The latter makes it difficult to capture the detailed dynamics of technology-specific innovation trends using national or sectoral innovation systems approaches [38].

So far, most studies on technological innovation systems focus on technological transitions in developed countries [9]. These include the diffusion of renewable energy technologies in Germany, Sweden, and Netherlands [39] [40], or the evolution of photovoltaics in Germany [41], wind energy in California, USA [38], biomass in Germany [42], and comparative studies of photovoltaics in Japan and Netherlands [43], and offshore wind in the UK, Denmark, and Germany [44]. The relatively fewer studies on emerging economies are mostly on photovoltaics [45] and wind energy [9] in China. Beyond innovation systems literature, there are also an increasing number of studies on sustainability and low-carbon energy transitions focusing on developing or emerging (or newly developed) economy contexts [46-48]. While these studies use a diverse set of theoretical frameworks, their insights point to the systemic nature of these sociotechnical transitions [49]. To better study transitions in emerging economies, we build on the existing literature, particularly the structural TIS framework in [38], and propose an approach which accounts for conditions that are present in these contexts, such as the differing capacities for financing and infrastructure. Further, we shift from the conventional focus on technology diffusion as the primary focus of an innovation system [30] to one where technology-specific policies can stem from broader developmental goals. For example, import-substitution policies, which aim to protect domestic manufacturers from foreign competitors, are often rooted in national priorities for growth and yet can have a strong influence on the diffusion of a technology. This is seen in the development of heavy industries in India before economic liberalization [50] and in the evolution of automotive and telecommunication industries in China [51]. With this rationale, we propose six components of a technology innovation system 
framework, which together can be considered as the building blocks of the technology innovation value chain in a developing country context [34, 38]:

1. Technology policy: the policies and policy institutions targeting the technology, such as technical standards, domestic value-addition requirements, or more broadly those governing industrial clusters, intellectual property laws, and climate policy. National ambitions, beyond the sole emphasis on the diffusion of technology, are included.

2. Technology supply-side: raw materials supply, the manufacturing and assembling of components that comprise sub-systems of the technology, and testing labs for product performance.

3. Technology demand-side: the actors involved in sale, distribution, marketing, and procurement of the technology, individuals or firms (typically local small-scale enterprises) who provide installation and maintenance services, and the end-users.

4. Infrastructure and technological spillovers: infrastructure requirements and technological spillovers such as technical know-how from other industries, and inter alia electricity, roads, and telecommunication.

5. Knowledge institutions: to provide education, vocational training and consulting, $R \& D$, and networking organizations which facilitate knowledge dissemination within industry, technical, and lobbying groups.

6. Financing: public and private sector entities that provide financial support to industrial enterprises and other actors across the innovation system. This includes government institutions who provide R\&D funding and support to industrial enterprises, banks, venture capital and angel investors, as well as firms providing financial management services.

\subsection{Methodology}

The second stage of our approach comprises of applying this framework to examine India's LED transition. To do so, we undertook an extensive document analysis of research and policy materials (e.g. LED technical specifications, government reports and databases, government tenders, and company reports), and conducted interviews with over 25 actors, in 2018-2019, including influential actors, such as, senior officials in government, heads of multinational 
companies, leaders within scientific research institutes, implementers of policies, and end-users of the technology. The interviewees were selected in three ways: (1) through an extensive mapping of relevant solid-state lighting government and private sector organizations and their respective heads and leaders; (2) authors of and experts cited in Indian research and policy reports, government tenders, official documents, and company reports; and (3) additional national and international experts recommended by interviewees. These interviews were conducted via phone, video calling, and in person. The interviews were focused on a set of key topics, including the global and domestic SSL landscape, particularly as limited quantitative and qualitative data is available on the status and evolution of the Indian SSL R\&D industry and market. The interviews also focused on the design and implementation of SSL-related policies in India, their implications for manufacturing; and future opportunities and challenges for the SSL R\&D, industry, and policies landscape. We emphasized uncovering the drivers of India's LED transition, and its intended and unintended consequences, which are not captured in publicly available analysis. Each interview lasted 60-90 minutes. In some cases, follow-up questions were asked and a written list of topics to be covered during the interview was provided to the interviewees who requested this information. More detail on the interviewees and interview questions is provided in the Supplementary Information.

We do note, however, that while this is among the first detailed studies on India's LED transition, it is still limited by the paucity of publicly available data. Specifically, the availability of data on the trends in domestic value addition in LED lamps, imports of LED lamps and components, production volume of manufacturing units, and jobs created in the Indian LED industry would have helped quantify different performance metrics for the lighting innovation system. In addition, while we capture the role of transnational influences in the evolution of technological innovation systems (e.g., the link between China's LED manufacturing (over)capacity and rapid market creation in India), a comprehensive account of such influences would require a comparative study of the LED TIS in India and China, which was out of scope for this paper but presents a promising direction for future research.

In the next section, we discuss the data collected and its analysis in detail. 


\section{Results: Evolution of residential LED lighting in India}

In this section, we examine the activities and arrangements for India's LED growth that took place under each of the framework's six components. Taken together, we assess the implications for how an emerging economy can leapfrog to low-carbon technologies. Figure 3 summarizes the results of populating the framework components with the collected data.

\begin{tabular}{l|l|l|}
\multicolumn{1}{c}{ Knowledge Institutions } \\
& Knowledge base of R\&D in materials and LED chip \\
Research institutions isolated from manufacturing ecosystem \\
Lighting industry associations and networks \\
Industry R\&D on designing electronics, 'smart' lighting \\
- Skill development not to necessary scale
\end{tabular}

Figure 3: TIS framework applied to the Indian solid-state lighting sector.

\subsection{Technology policy for solid-state lighting in India}

India commenced policies and initiatives for LED lighting in 2007-8 (Figure 4), beginning with an SSL-focused R\&D funding program, followed in 2012 by internationally aligned technical standards for LED lamps and their components, and subsidies for capital expenditure on LED lamps and component manufacturing $[17,52]$. Other relevant policies include domestic value- 
addition requirements for procured LED bulbs, compulsory registration for domestic and foreign manufacturers supplying to the Indian market and restructuring of the LED-related import tariff structure.

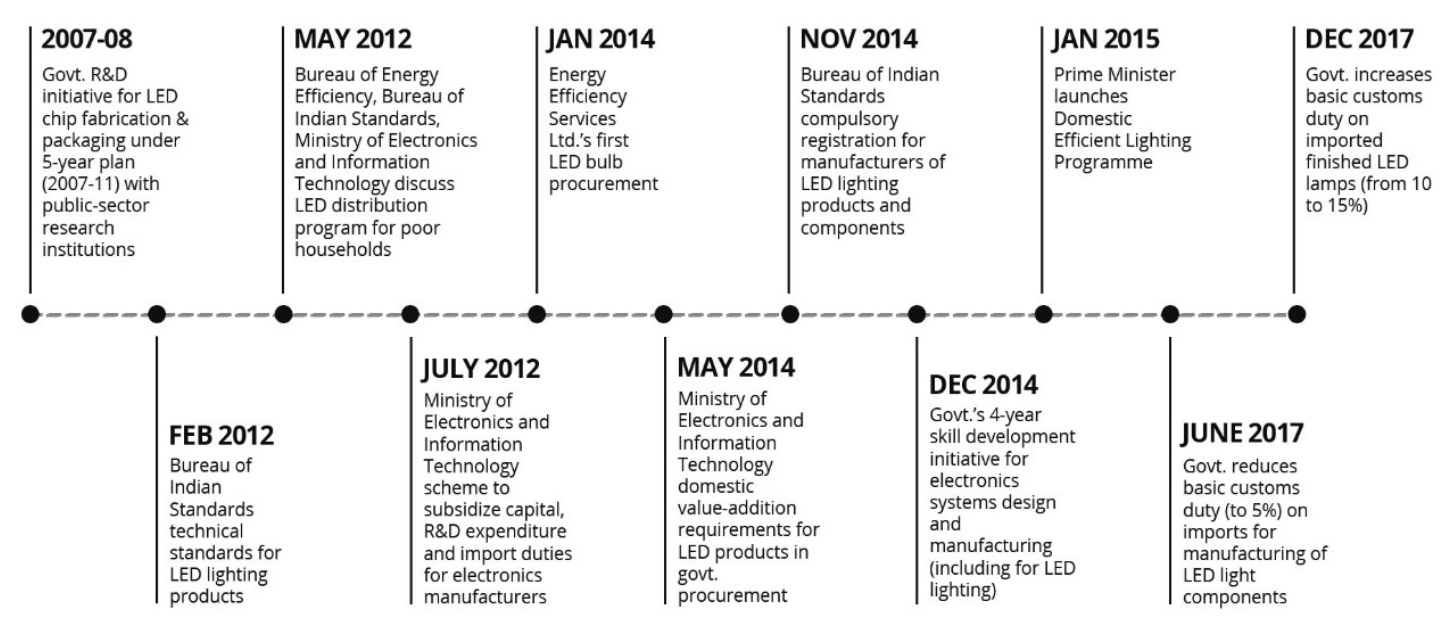

Figure 4: Timeline of notable policy initiatives in the Indian solid-state lighting sector

It was in 2014, however, that the impact from different policies saw a sea change when the government introduced the Unnat Jyoti by Affordable LEDs for All (UJALA) program, identified by some as the 'world's largest zero (direct) subsidy LED bulb program for households' [53]. The program targeted the residential sector, which accounted for $23 \%$ of the country's total electricity consumption in 2015-16, and aimed at replacing about 770 million incandescent bulbs by LED lamps [54]. In the five years since its initiation, the annual sales of LED lamps in India grew hundred and thirty-folds to about 670 million LED bulbs sold in 2018 (Figure 1). The estimated size of the country's lighting industry is currently INR 200 billion (USD 3 billion) of which 70\% comprises of LEDs [20], which amounts to more than $40 \%$ of all lamps sold in India [15].

The policy innovation that enabled this growth lay in using demand aggregation as a means to reduce the technology's price. The Indian Ministry of Power's Bureau of Energy Efficiency supported the creation of a joint venture between four public sector utility companies, called Energy Efficiency Services Ltd. (EESL), which served as the interface between the government, 
private sector companies, and consumers. To procure bulbs at a large scale for the national market, competitive bidding was used to bring down the price of LED bulbs. The price of the LED bulb prior to the program was INR 1200 (USD 17) in 2009 and INR 400 (USD 6) in 2014. The competitive bidding and economies of scale enabled bargains for significant discounts from manufacturers (both Indian companies and foreign multinationals), which were then partly transferred to consumers by selling the bulbs at significantly lower prices (about INR 70 (USD 1)) than the retail market price (more than INR 100 (USD 1.5)).

Successive bids saw substantial price reductions as the quantum of orders increased - starting with an LED bulb price at INR 200 (USD 3), to INR 140 (USD 2), and finally to INR 38 (USD 0.6 ), a price drop that is proportional to that in the international market [22].

As indicated throughout our interviews with heads of large and medium-sized, domestic and multinational companies in the LED lighting industry,

“EESL became the biggest catalyst for the LED revolution, and they've brought India on the global solid-state lighting map."

"The technology got adopted in 6 months, while it should have taken 5 years."

"As a result of the EESL program, the LED bulb is now cheaper than bread!"

The policy design paid equal emphasis to distribution, as it did to procurement. EESL signed agreements with electricity distribution companies to distribute procured bulbs in their territories. Consumers could buy bulbs at kiosks at the distribution companies' customer service centers or from vendors hired in each state, by paying the full price upfront or through monthly instalments via electricity bills. EESL's small team effectively coordinated the supply chain with vendors across the country, which at the peak of the program sold 600,000 LED bulbs per day [53]. As described in the interviews by experts, "this model worked as the distribution companies got the credit while EESL got the sales," and "EESL's implementation is transparent and better than that of most other government bodies."

On the flip side, the distribution model of selling via utility centers, although potentially faster, risked disenfranchising approximately 400,000 local retailers in the supply chain, who began 
losing their consumers to EESL's LED bulb kiosks. In the words of the business head for a multinational company, "the consumer needs the lamp to be at his corner store - but the creation of such a sustainable ecosystem was bypassed." "The retailers/shop keepers felt out of loop with the ESSL program as it stopped consumers from coming to their shops (with a sense of affecting their livelihoods), because LEDs were being sold directly from the EESL kiosks." "Ideally, all the 1 million stores should be carrying the LED products from the start so that can also deal with replacement, warranty, etc." To ameliorate this concern, "EESL's response was to put out a bid for half their projected demand, so that the other half can be provided via retail outlets," in the words of a senior government leader.

Finally, central to the policy model were innovative marketing initiatives, including a dashboard with real-time updating of the number of LED bulbs sold (with their estimated energy saved and $\mathrm{CO}_{2}$ emissions reduced), and numerous local-level campaigns through $\mathrm{TV}$, newspaper, and mobile advertising. The dashboard was often cited by media and politicians, which increased the strong political ownership of the program ("the program became a poster child"), and enabled linkages with broader objectives of India's energy and climate change policies [55].

The results from the demand aggregation policy of 2014 thereby dominate the India's LED landscape, in spite of the much older history of SSL policies (as seen in Figure 4). Demand aggregation was complemented by other policy elements, such as innovative marketing initiatives to increase public awareness and acceptance of the LED lighting technology, and the domestic value-addition requirements in the procurement tenders to promote domestic industrial capabilities discussed below.

3.2 Supply-side of LED technology including raw materials, manufacturing and assembly

The value chain of LED lighting technology consists of: (1) semiconductor wafer fabrication, LED chip production, and packaging; (2) design and production of a driver integrated circuit; (3) design, production and assembly of the printed circuit board; (4) production of optical components (lens, reflector, and diffusor); (5) production of the heat sink; and (6) assembly of 
LED lamps from these components and subsystems. The evolution of LED technology has been driven by $R \& D$ in material sciences and electrical engineering [56] across its value chain.

Historically, India has not had a commercial semiconductor wafer fabrication facility [57] and subsequently LED chips and driver integrated circuits (two core components of a LED lighting system), for almost all bulbs in India, are not manufactured domestically. Indeed, India remains largely dependent on imports of components and finished SSL products from China, as its domestic manufacturing could not expand at a rate commensurate with market growth. As stated by an industry leader, "India is largely dependent on imports for electronics/components industry and does not have the requisite indigenous capabilities for creating components, leading to subsystems, and then to products." In effect, China's overcapacity of low-cost largescale LED chip manufacturing [25] enabled India's growing demand to be met through imports of LED lamp components.

As suggested by a senior policy maker, "the first goal of the LED program was to make the bulb easily available, and then to create manufacturing in India". While a few Indian companies tried to enhance domestic supply and set up semiconductor fabrication facilities (e.g., Kwality Photonics Pvt Ltd [58], De core Nanosemiconductor [59]), they have not yet succeeded in setting up a commercial fabrication unit.

To promote domestic manufacturing within this environment, the government's LED lighting procurement tenders adopted provisions for small manufacturers, and for domestic valueaddition requirements starting in 2016 (initially of at least 50\% domestic value addition in at least $50 \%$ of the procured stock) [60]. These provisions were in line with the Department of Electronics and Information Technology's existing directives for government procurement of LED lighting products $[60,61]$. The implementation of these requirements, however, led to mixed results, as often domestic value addition was overestimated - for example, the entire value of an LED driver was considered to be a domestic addition, even if technically only $30 \%$ of the LED driver parts were domestically manufactured [61]. 
In spite of these limitations, the technology's supply-side ecosystem in India evolved with the success of the LED program. India's domestic SSL manufacturing activities have grown to include assembly of LED lamps from partial and non-assembled parts, manufacturing of heat sinks, optical components, and printed circuit boards, along with the assembly of electronic components onto the boards. Starting in 2014, the government required all LED bulb and components manufactures supplying their products to the Indian market to register with the Bureau of Indian Standards (BIS) ${ }^{1}$. By 2018, India had more than 400 registered manufacturing units of LED bulbs, luminaires, and their control electronics, most owned by small and medium enterprises that manufacture for bigger companies and a few units owned by foreign multinational companies like Philips [62].

Product quality is an important dimension in examining the technology supply-side because it is strongly influenced by trends in technology innovation, industrial capabilities, technical standards and their enforcement. The number of accredited testing laboratories for LED bulbs in India increased from three to fifteen during 2014-2016. While the government's policy model requires quality testing of the LED bulb at manufacturing, supply and use, our interviews suggest that these more stringent quality control guidelines were not necessarily followed. Part of the reason, as explained by a domestic lighting company head, is that "The support system for $R \& D$ in India is very limited. There are few research labs where you can check your experiments and companies cannot own all the machinery in-house to do testing. Access to testing labs in an important need of the hour."

Further, majority of our interviewees noted that manufacturing companies found it difficult to keep up with the government's (i.e., EESL's) aggressive low-price bids, and were inclined to cut costs by potentially undercutting bulb quality. As mentioned by experts during interviews,

"Companies bid so low and are trying to undercut each other, which can disrupt the value chain."

\footnotetext{
1 The government of India requires manufacturers of LED bulbs, luminaires, and components supplying to the Indian market to register with the BIS database of manufacturers. Although the mandatory registration policy is coming into effect in phases, the numbers registered increases after 2014.
} 
"The biggest LED manufacturers in China are also not able to match quality at the low price point prevalent in India."

"The last bid price is too low to produce a robust product."

The limited emphasis on quality is also reflected in the government's tender specifications regarding useable life and lumen maintenance of procured LED bulbs, which were not as stringent as global standards. "Tenders are not pushing the boundaries of LED technology. They are less than the specs outside India," said a multinational company leader. As LEDs do not 'burn out' like incandescent lamps (ICLs) and CFLs but rather get dim over time, a LED bulb is said to have reached the end of its life if it stops working because a component other than the LED chip, such as the driver integrated circuit, has failed, or if it dims below a specified level of brightness. To test the latter possibility, the only standardized way to specify 'usable life' of LED bulbs is by measuring 'lumen maintenance', i.e. how long the bulbs maintain their brightness, typically considered to be the time for which the brightness is at least $70 \%$ of its maximum brightness at the beginning of its life. The international standard for the procedure of measuring LED bulb brightness over time is the "LM- 80 " of the Illuminating Engineering Society [17]. Because the usable life of LED bulbs is typically more than 10,000 hours and testing lumen maintenance for that long is impractical, another international standard ("TM-21" of the Illuminating Engineering Society [17]) specifies a model to calculate the usable life by extrapolating LM-80-based measurements over 6,000 hours. The Indian BIS standard (IS:16102 part 1 and 2-2012) follows the LM-80 specifications for measurement procedure, but instead of using the extrapolation model of TM-21 to calculate usable life, assumes compliance of lumen maintenance after 25 percent of the lifetime or 6,000 hours, implying that the lamps have a nominal life of 25,000 hours. EESL tenders specifically list the lifetime requirement of LED bulbs as 25,000 hours, to be measured using TM-21 [60], but require 'lumen maintenance' based on IS:16102 (part 1 and 2)-2012 to be $80 \%$ brightness by 6,000 hours. As per the BIS standard, this lumen maintenance specification assumes 25,000 hours life, but our calculations based on the TM-21 model imply that the specification can be met with 10,000 hours of usable life ${ }^{2}$. This is significantly shorter than the standard LED bulb usable life of 25,000 hours in the US [17] and

\footnotetext{
${ }^{2}$ As per the TM-21 standard, given LED bulb brightness L0, L1, and L2 at times 0 , t1, and t2 respectively, $\ln (\mathrm{L} 1 / \mathrm{L} 0) / \ln (\mathrm{L} 2 / \mathrm{L} 0)$ $=\mathrm{t} 1 / \mathrm{t} 2$. Thus, $80 \%$ brightness at 6,000 hours imply $70 \%$ brightness at 9590 hours.
} 
of 15,000 hours as per technical specifications released in 2013 by the Electric Lamp and Components Manufacturers Association of India [63] (although lower-quality LED bulbs are also available in the retail market). "There is the aim of getting to the lowest price to reach the market (executed flawlessly by EESL) but we are not sure if it created a good lighting experience," said the CEO of a lighting company. "The tendering model is both good and bad. Anyone can compete for a low price irrespective of the quality of their products, and even if they do not fully understand LED manufacturing and fixtures. So, while, manufacturing capacity is increasing, it is not pushing India to be globally competitive."

Further, the warranty of LED bulbs sold through the policy program dropped from 8 years in 2014 to 3 years in 2015 [53], suggesting reduced quality of LED bulbs in EESL's subsequent tenders. Using an estimate of 8 hours of daily use, a bulb with 10,000 hours of usable life would last for about 3 years, consistent with the reduced warranty period. As described by an expert, "[companies have] products of different quality ... the lights with the lowest price are not bad but they are not the best in class. They will meet the 3 years [lifetime requirement] that is in the tender." In words of the head of a multinational company, "EESL did help create a critical mass of manufacturing ecosystem in India. It wouldn't have happened organically. But what it did not create is a higher value-added ecosystem". According to the head of an SSL-manufacturing company, “[competition towards] lowering costs has disincentivized [the industry's] investment in $R \& D$. Why invest in $R \& D$ when you can get $50 \%$ of the market share with a low-quality product? ... local innovation is incentivized through the market economy." However, limitations of the electric grid did necessitate some industrial R\&D, as discussed in Section 3.4.

Diversity in the quality of technological products exists across global markets. However, the findings from the Indian example highlight the trade-offs between an innovative policy model to rapidly create a large market and ensuring longer-term quality of the low-carbon technology.

\subsection{Demand-side of the LED technology}

Creating market demand for LED lamps, with a combination of low prices and sophisticated distribution channels, was central to the Indian policy strategy. As LEDs became price 
competitive, they began replacing CFL bulbs. "The CFL business has almost stopped with the rise in LEDs," mentioned an interviewee. Emblematically, the largest CFL plant in the country was closed down [53]. The incandescent bulb remains the cheapest lighting product in the market (INR 10 (USD 0.15)), yet, the sales of LED bulbs in India overtook those of incandescent bulbs in 2018, even without policies mandating phase-out of the latter, suggesting a steady and growing consumer demand. The creation of the LED market has been concurrent with the expansion of electricity access in India ${ }^{3}$, which is increasing the installed base of lighting connections across the country. New studies show a trend towards first-time LED use, such as in low-income households [64], and in peri-urban and rural areas [65].

Another important aspect of understanding technology demand is to examine the systems for maintenance, replacement and warranty. We find that by distributing LED lamps through utility service centers and selected vendors, the traditional distribution chain in the retail market was bypassed, which plays a key role in ensuring replacement during warranty. As illustrated in a concern put forward during our interviews, "when you buy from an EESL kiosk outside the utility center which is not permanently there, it is not clear where to go to for repairs." Studies suggest that although the failure rate of LED lamps sold through the program is found to be much higher than the officially reported rate of $1 \%$, consumers are deterred by the tedious replacement processes in government's policy scheme [53]. The overall effect of warranty and replacement is yet to be fully determined. As mentioned by a senior policy researcher, "The first wave of consumers who bought potentially lower quality products will require replacement 3 years down the line. At that stage the private players will likely come in and leverage better quality, and it will then be a decision between better quality and not."

Product quality is an important dimension also from the demand-side perspective as it affects the total cost of ownership (low-quality short-lasting bulbs require frequent replacement) and consumers' purchase and repurchase decisions. As discussed previously, competition for the least price forced the retail market to drop their costs by reducing the quality and warranty period of LED bulbs. On the other hand, because a large part of the manufacturing infrastructure for

\footnotetext{
3 93\% Indian population has electricity access in 2017 as per the World Bank data, https://data.worldbank.org/indicator/EG.ELC.ACCS.ZS?locations=IN (accessed October 5, 2019).
} 
ICL and CFL bulbs was reconfigured to assemble LED bulbs, reducing the supply particularly of CFLs, consumers are less likely to switch back to older lighting technologies despite the quality issues with purchased LED bulbs.

\subsection{Role of infrastructure and technology spillovers}

Infrastructure and spillovers from other technologies and industries play a key role in enabling or hampering technology advancement. Infrastructural weaknesses are among the systemic problems that can slow down clean energy technology adoption [66], and in contrast, interindustry technological spillovers are seen to benefit the growth of clean energy technologies (e.g. the benefits to the photovoltaic industry from semiconductor and other industries [67]). These are even more critical in emerging economies where infrastructural transitions are ongoing and technological capabilities are often underdeveloped.

In India, LED manufacturing capabilities benefited from spillovers from incumbent lighting technologies, such as CFLs, along with other industries. For instance, many lighting product manufacturers and electronics manufacturing service providers converted existing CFL assembly lines or set up new units to assemble LED lamps, aided by an existing infrastructure and knowhow on how to design, print, and assemble circuit boards. Philips Lighting, for example, had two of its largest factories in India, manufacturing incandescent bulbs and CFLs (including for export). In 2016-17, the company invested INR 782 million (USD 12 million) to reconfigure the manufacturing equipment and lay off workforce engaged in manufacturing of older lighting technologies [68]. This spillover effect was beneficial even though it incurred additional costs, as the costs and time required for reconfiguration of manufacturing infrastructure were less than that for setting up new factories. In another case of spillover benefits, as mentioned by an industry expert during interviews, "in the mechanical [components] area-lamp encasing, luminaire, optics, etc. - India has very good skills and industry capabilities which are built from a thriving automobile manufacturing industry."

However, such spillovers were not possible in manufacturing LED chips and the driver integrated circuits because of the absence of an established semiconductor fabrication industry in 
India and a lack of supporting industries. Required chemicals, such as ultra-pure hydrogen and nitrogen gases used in LED chip fabrication are critical in achieving high efficacy of LED chips. According to a senior public-sector SSL researcher interviewed, "[these] gases need to be imported which makes [building] infrastructure very difficult and companies can't start manufacturing facilities. [Research institutions] can get [pure] gases but the quantities are much smaller. It takes about 6 months to import, and the shelf life of the gas expires by then”.

In addition to the role of infrastructure in technology spillovers, additional dimensions, such as the quality of electricity supply, and local dust and humidity conditions are important. As mentioned by a senior technology researcher, "the initial set of imported LEDs tested by EESL failed because of the humidity and dust entering into them." Indeed, from the early stage of the LED program it became clear that the imported LED lamps could not withstand India's highly fluctuating voltages of electricity supply (which drop to $180 \mathrm{~V}$ AC compared to the standard 220$240 \mathrm{~V}$ AC that the imported chips were designed for [69]). According to the head of a large multinational company, "the Indian grid fluctuations are very high-150-370 volts is more real than the official 200 volts... Without $R \& D$ related to power conditioning, a global product will fail in these conditions in a few months." As a result, original equipment manufacturers, including multinational enterprises and a few manufacturing service-providers developed domestic R\&D capacity to design high-quality electronics subsystems to withstand the electricity fluctuations. Although weakness in the electricity infrastructure in India motivated some industrial R\&D activity of this nature, the R\&D-led product design did not prevent the overall decline in LED bulb quality as reflected in the warranty period reduction.

\subsection{Institutions for knowledge creation and dissemination}

It is clear that India has historically lagged behind in global electronics systems design and manufacturing research, and particularly on SSL. In part, this is a function of an absence of frontier industrial R\&D and the late entry by Indian public-sector research institutions and universities in SSL R\&D (in comparison with counterparts in the USA, Japan, Germany, China and South Korea). India's first major R\&D program on SSL was launched by the Department of Scientific and Industrial Research (DSIR) under the $11^{\text {th }}$ five-year plan (2007-8 to 2011-12) to 
develop indigenously fabricated LED chip and gallium nitride material growth [70]. However, as learnt during interviews with the researchers, the initiative could only develop LED bulbs with $33 \mathrm{~lm} / \mathrm{W}$ luminous efficacy ${ }^{4}$ - compared to $100 \mathrm{~lm} / \mathrm{W}$ efficacy of China-manufactured LED bulbs sold under UJALA [60].

As the R\&D program continued beyond 2012, India began emerging as a prominent country in SSL research, with the sixth highest high-impact research articles in the field during 2013-2017 (Figure 5). In relation, USA and Japan led on high-impact SSL research articles until the turn of the century, China's position grew enormously from 2005, and India's output expanded from 2013 to catch up with Japan, Germany, and Taiwan - three of the leading countries in SSL R\&D and manufacturing.

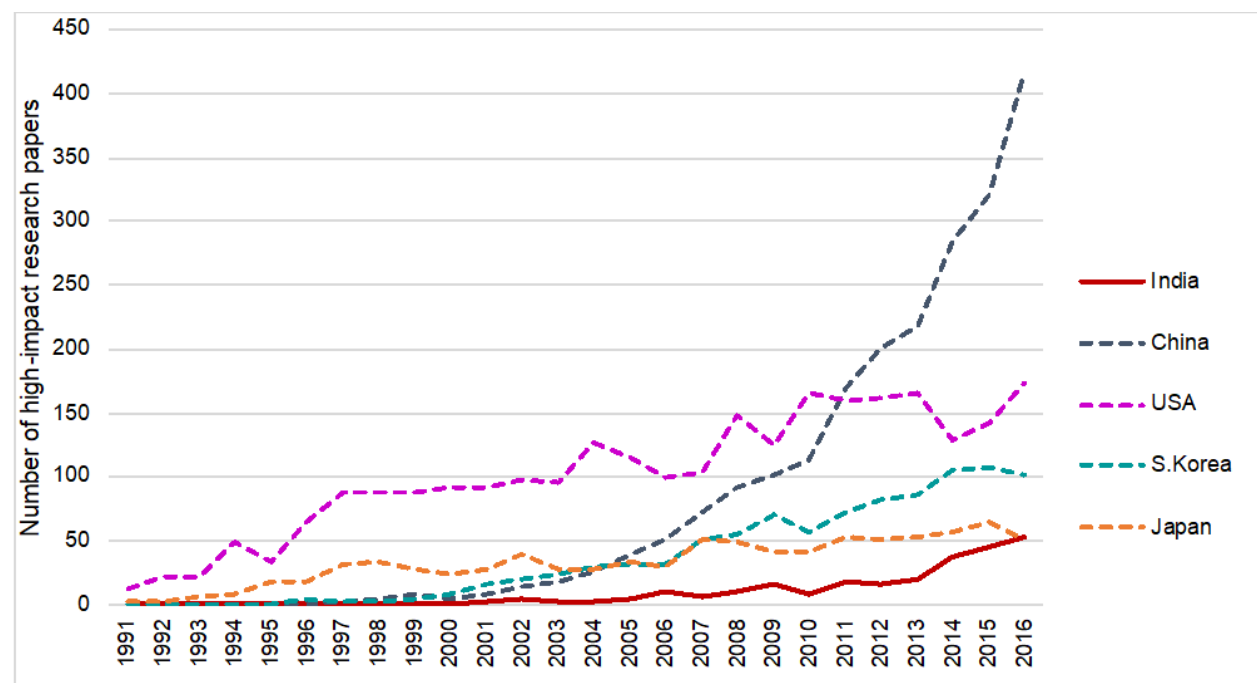

(a)

\footnotetext{
${ }^{4}$ Lumens $(\mathrm{lm})$ is the measure of brightness of a light source. Higher the $\mathrm{lm} / \mathrm{W}$ efficacy, more efficient is the light source.
} 


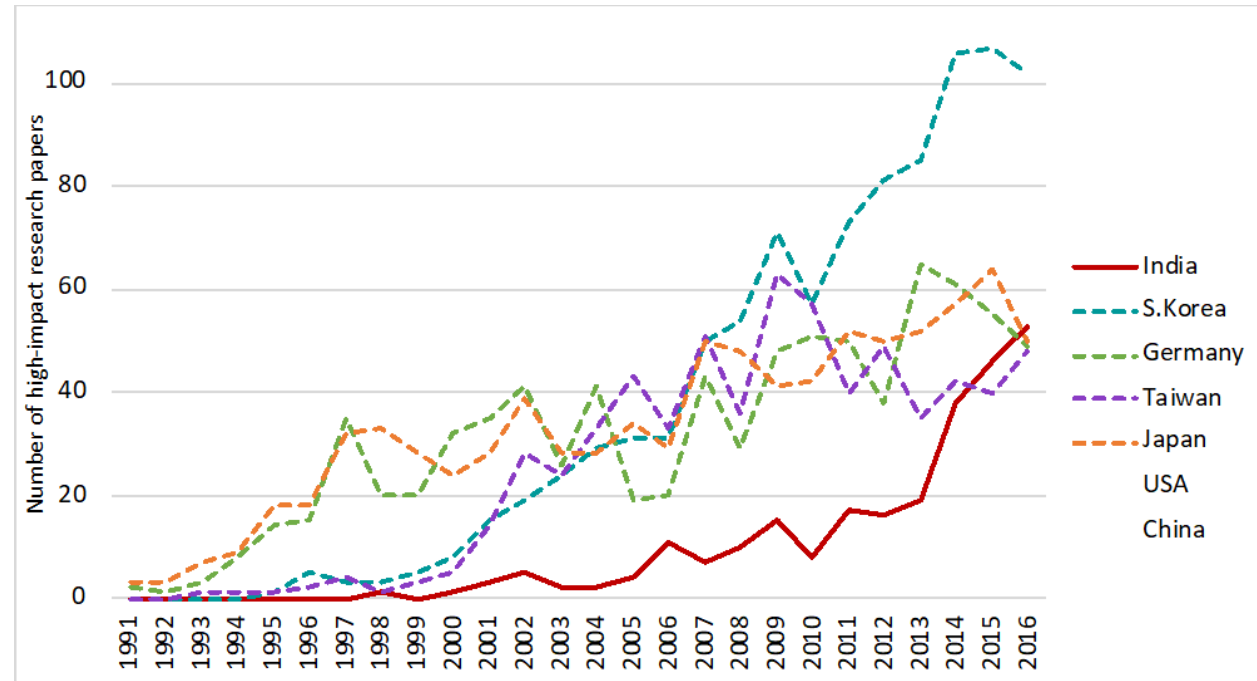

(b)

Figure 5 Trends in 'high-impact' peer-reviewed research articles on SSL research by authors' countries. The charts were generated using the 'Web of Science Core Collection' database, by searching for papers which include variants of terms 'light emitting diode' or 'solid state light' in the title, abstract, or listed keywords and then selecting the top 10\% 'highly cited papers', normalized by their respective field and publication year. (a) shows high-impact articles from India, China, USA, S. Korea, and Japan. To see trends for countries other than China and USA, (b) shows a zoomed-in version of the vertical axis in (a) along with trends for Germany and Taiwan.

Delving deeper into the nature of research undertaken, however, sheds light on the dissociation between the India's LED market formation and its larger ecosystem of SSL research. Heads of large multinational companies were clear about having had "no collaborations with national labs or research institutes" and for the "need for more industry-government and university linkage for a better SSL ecosystem." "The LED policy program was conceptualized with little engagement from academia, even though universities can play an important role," they mentioned. The interviews corroborate that industry, and university and public-sector research are isolated from each other. Academic and public sector researchers were not involved in designing the government's successful LED policy program, nor were they central to defining the LED standards issued by the Bureau of Indian Standards. Indeed, industry experts and executives 
interviewed knew little about specific R\&D programs in India's university or research institutions.

Finally, access to skilled labor - which is essential to knowledge creation and dissemination has been a major challenge for the electronics systems design and manufacturing industry, including SSL manufacturing. Since 2014, the Indian government is developing programs, in cooperation with the private sector, to address the shortage of skilled labor in this industry. Their success is restricted, and the programs have trained less than 300,000 candidates for jobs in the entire electronics systems design and manufacturing sector till 2018, compared to its projected demand of 5.3 million skilled personnel over the next five years $[45,71]$. This is relevant for other demand-side low-carbon technologies (such as renewables, energy efficient airconditioners or fans, among others), which do not have the advantage that LED bulbs do of not needing a skilled technician for installation.

\subsection{Financing technology innovation systems}

One of the challenges of large-scale deployment of low-carbon technologies is having the financing of appropriate nature and scale. India's LED program architecture drew from the lessons of a previous scheme to promote CFLs [72] which suffered, in part, from being financially reliant on a volatile international carbon market ${ }^{5}$. Instead, the LED program relied on an efficient and transparent e-bidding process for bulk procurement of bulbs at the national level and, unlike the CFL program, remained delinked from international carbon markets.

There have been two major financing-related challenges in setting up LED chip and integrated circuits fabrication and bulbs manufacturing in India $[58,73]$ (as corroborated by expert interviews in industry and research institutions). First, given the dominance of China and Taiwan in large-scale low-cost semiconductor manufacturing and the concentration of relevant intellectual property with a few global players, it is difficult for an emerging economy to attract

\footnotetext{
${ }^{5}$ The CFL program was financed through an international carbon trading scheme, established under the Kyoto Protocol. The program could not scale mainly because, when the carbon prices in this scheme crashed, the implementing agencies found it too risky to invest in it [53] Chunekar AM, Sanjana; Kelkar, Mrudula. Understanding the impacts of India's LED bulb programme, "UJALA". 2017. http://www.prayaspune.org/peg/publications/item/download/800_f0b95c623a9c2c6a9c6f64a58d8d0a1e.html. .
} 
sufficient investment in this capital-intensive sector. Second, historically, finished electronics products had lower import duties in India than the components required to manufacture the products domestically, making it more difficult for Indian manufacturers to compete with lowcost imports.

As a result, the Indian government's fiscal support for LED lighting includes subsidy schemes for capital investments in domestic manufacturing and exports and correcting the inverted imported tariffs. As discussed earlier, financing that contributed to the market growth came mainly from two avenues: (1) EESL, which invested in the bulk procurement program and marketing campaign, and (2) from industry that invested in reconfiguring their manufacturing infrastructure. To incentivize capital investments in manufacturing, one scheme subsidized 20$25 \%$ of the R\&D and other capital expenditure (countervailing duties on manufacturing equipment ${ }^{6}$ ) and $10 \%$ of the production turnover from assembling, testing, and packaging LED bulbs and their components including semiconductor wafers [75]. The applications that the government received to avail these subsidies, from companies interested in setting up or expanding India-based manufacturing of various electronics products including LED bulbs, amount to proposed investments of over USD 16 billion for electronics manufacturing reflecting the growing interest of industry players. At the same time, between April 2014 and March 2019, approximately USD 70 million subsidies were disbursed by the government to electronics manufacturing companies whose subsidy applications were approved, which amount to less than $5 \%$ of the government target [75-77]. In addition to promoting exports of domestically manufactured electronics, there are Special Economic Zones exempt from income tax on the export profits from their manufactured products, and since 2017, duties on LED manufacturing parts have reduced and customs duties on finished LED lamps increased, to restructure the previously inverted duty structure [76].

Data is not publicly available on whether and how any companies that received specific subsidies contributed in the bulk procurement supply chain. Nonetheless, the growing number of

\footnotetext{
${ }^{6}$ In 2017, the subsidy for import duties was replaced by a 10\% subsidy on production turn-over [74] DeitY. Amendments to Revised Modified Special Incentive Package Scheme (M-SIPS). In: Department of Electronics and Information Technology (DeitY) of Ministry of Communications and Information Technology GoI, editor.2017. http://meity.gov.in/writereaddata/files/msips_notification.pdf.
} 
applications for these subsidies show the increasing interest of the industry in SSL manufacturing in India - at least in part, a result of the enormous market potential demonstrated by the bulk procurement program and the resulting rapid market expansion. The manufacturing capacity, being created through these subsidized capital investments, is expected to contribute to further growth and sustainability of the domestic SSL market and manufacturing. Recognizing the success of the LED program, the World Bank in 2018 approved loans of USD 220 million to support the government's policy initiatives [78].

\section{Discussion: Assessing India's LED lighting technology innovation system}

An analysis of the empirical findings for each of the six components of the technology innovation system framework, when considered together, provide important insights about the empirical trends, successes and missed opportunities from the Indian LED transition, including, the importance of each component in the transition. These are encapsulated in Figure 3. A pressing ensuing question is what would the implications be if the bulk procurement policy process ceased, and would LED bulbs continue to replace less energy efficient incandescent bulbs? In this section, we reflect on this question as we assess India's LED technology transition and innovation system as a whole.

An investigation of all six components of the Indian LED TIS and their interrelationships provides a deeper understanding of the conditions that enabled the lighting transformation, beyond the specific design and implementation of the policy program. First, while the government's LED policy program led by EESL was the primary driver of India's transition to LED lighting, China's overcapacity to manufacture LED bulbs and their components at scale and low cost was a crucial supply-side enabler of the program's success. This aligns with the findings in the literature that sustainability and low-carbon technology transitions in developing countries are strongly influenced by transnational dimensions [79, 80]. Second, the expansion of the domestic assembly-level manufacturing of LED bulbs could meet the domestic content requirements in the LED program tenders because the manufacturing infrastructure for incandescent and CFL bulbs could be reconfigured and repurposed to assemble LED bulbs, including at the Indian factories of multinational companies. At the same time, the weak 
enforcement of domestic requirement standards and limited quality testing also contributed to a more rapid transition towards the supply and demand of the bulbs. Both enabling conditions were central to successful market creation and adoption. The rapid LED market expansion was thereby not a result of a single policy initiative but of the alignment and interactions between multiple trends in the innovation system. In an affiliated trend, India rose in global SSL research publications within a decade since the launch of its multi-institute R\&D program.

The results also show that the success of LED transition in India coexists with a share of shortfalls. Specifically, there is an important tension between the lowering of upfront costs of low-carbon technologies and the efforts to enhance domestic technological capabilities. The Indian policy program chose to focus on aggregating the demand and creating a market, which it successfully achieved. However, the focus on some, and not all, components of the innovation system has resulted in manufacturing and R\&D capabilities in industry not growing as fast as the market demand. Industry also remains disconnected from complementary advances in the academic research ecosystem.

It is likely that the increased Indian market demand for LED bulbs, rise in manufacturing activities, and relative growth in the number of testing laboratories in India will sustain over time. However, in spite of the program's overall direction and speed of travel, a deeper look at the individual components of the technology innovation system show varying degrees of success at best. Importantly, when considered as a whole, there is a distinct lack of consistent strategic action across all the interacting dimensions of the technological innovation system.

With the growing demand for LED bulbs and the related reconfiguration of a large part of the manufacturing infrastructure for ICL and CFL bulbs, the supply of CFLs in the market has reduced. In addition, LED bulbs are now marketed and available across the country, and their associated reduction in electricity bills is increasingly well known. Sudden withdrawal of the government's bulk procurement program is thereby unlikely to result in customers turning back to less efficient lighting technologies. At the same time, continuing the policy program's competitive bidding process also risks further deterioration of the quality of LED bulbs to lower the costs and disenfranchising retail vendors. This is likely to become a more prominent issue as 
first-time buyers of LED bulbs, who bought the government's policy program bulbs, look for replacements after the (relatively shorter) 3-5 years lifetime of these particular LED lights. Further, low-quality LED bulbs require frequent replacement, increasing the cost of ownership [21] and the embodied energy and emissions as compared to high-quality LED bulbs. Improving and maintaining the quality of LED bulbs is therefore necessary, and is also a precondition if Indian manufacturers are to become globally competitive exporters of LED bulbs and luminaires, including smart and adaptive lighting systems.

Given the weak R\&D and manufacturing capabilities that are often prevalent in developing countries, promoting low-carbon technology deployment needs to be balanced with ways to increase domestic industrial capabilities. It is often cheaper to import low-carbon standardized globally traded technologies, especially with the dominance of foreign manufacturers - China and Taiwan in the case of LEDs - which make it more difficult for domestic manufacturers to invest in building capabilities while also competing with low costs of imports. India is trying to balance these two dimensions with policy initiatives to promote domestic manufacturing, with initiatives such as 'Make in India', UJALA for LEDs, and the National Solar Mission for solar photovoltaics (with the $100 \mathrm{GW}$ deployment goal for 2022) [81].

Looking ahead to manufacturing LEDs in particular, an important question is whether it is necessary and economically viable for India to increase domestic value addition at this stage. We argue that there are three reasons why some level of domestic value addition is still opportune for India in SSL lighting technologies. First, adapting LED lamps to local conditions warrants at least design-level R\&D, which can happen domestically given that India has a strong electronics systems design ecosystem. Second, because India was a major manufacturer and exporter of ICLs and CFLs, it makes sense as a business strategy to transition to LED bulbs manufacturing when the market is transitioning to LED lighting. Third, domestic value addition makes economic sense given the projected heavy cost of imports, as semiconductor-based electronic products, including SSL and solar PV, are the second largest imports of India, after petroleum products, and are expected to exceed the latter by 2020 [82]. 
To determine which parts of the SSL supply chain it would be strategic for India to build its international presence in, we assess the value chain within the supply side of the SSL TIS. While in the early days of the technology, the LED chip was the most value-added part in bulbs and luminaires, this has since shifted to the control electronics subsystems, in simple LED bulbs as well as in more sophisticated tunable, adaptive, application-specific, and smart lighting solutions $^{7}$ [17]. Given the dominance of other countries in LED chip and driver manufacturing, the absence of commercial semiconductor fabrication in India, and the reduced share of these two components in the total cost of LED lamps, it is not advisable for India to try to compete internationally in this area. Instead, two areas in the SSL technology value chain appear to have a better growth potential, where the Indian SSL technology innovation system could leverage its existing strengths. First, is to focus on the control electronics surrounding the LED chip and driver, and software for 'smart' and adaptive lighting products, which have growing demand as well as an increasing share in the total cost of LED lamps. In this area, India could leverage its capabilities in electronics systems design and assembly [58] and in the software industry ${ }^{8}$.

In addition, next-generation SSL materials would be another strategic area for India to focus on, so as to develop a competitive advantage in the global SSL market. Our interviews with Indian academic SSL researchers indicate that India's research capabilities are growing in galliumnitride-based LEDs, which have been found to be more efficient than today's LED lights, and are candidates for next-generation LED lighting [17]. However, commercializing the research outputs requires strengthening the interface of research (academia and government labs) with the R\&D and manufacturing side of industry, which is currently missing.

Given these mixed results from the Indian case, we reflect on the insights from these findings for low-carbon technology innovation policy in developing economies in the next section.

\section{Looking Ahead: Low-Carbon Technology Transitions in Developing Countries}

\footnotetext{
${ }^{7}$ Refer to https://www.marketresearchfuture.com/reports/global-smart-lighting-market-960 (accessed October 5, 2019) for recent trends in smart lighting market.

${ }^{8}$ India ranks second in information and communication technology (ICT) services exports, after Ireland, as per World Bank data, https://data.worldbank.org/indicator/BX.GSR.CCIS.CD?most_recent_value_desc=true (accessed October 5, 2019).
} 
As countries around the world work towards their climate change goals, technological innovation, transfer and implementation of appropriate low-carbon technologies is essential. This is especially true in developing countries, where the importance of low-carbon technology development and transfer to assist in economic and sustainable low-carbon growth has been long recognized. Yet, the technology literature with developing-country points of view from a climate mitigation perspective is limited [6]. In examining the technology innovation system for India's LED transition, this paper also sheds light on the lessons and tensions for other developing country technology innovation systems in leapfrogging towards low-carbon forms. We discuss these in this concluding section.

First, policy interventions with a narrow focus on some, and not all, parts of the technology innovation system, although effective in the short-term, can have negative implications for the overall system. For instance, the demand aggregation and bulk procurement model in India triggered rapid, enormous growth of LED bulbs, making India a visible and major global LED market along with motivating expansion of domestic SSL manufacturing. However, the process of competitive bidding for the lowest cost also adversely affected the quality of the LED lamps and increased dependence on their imports. Further, there remained a lack of coordination between the government's EESL initiative and DSIR's SSL R\&D ecosystem, due to which technical capabilities in research institutions neither benefited market expansion nor informed technical standards and other policies. Therefore, while individual policies focus on specific aspects of innovation, a portfolio of coordinated policies that together address the entire system is required to sustain a full technology transition in the long term. While each policy needs to balance trade-offs between conflicting policy goals, coordination between different government agencies planning and implementing complementary policies can enhance and synergies amongst a larger set of outcomes. A forward-looking example where coordinated policies will be important is the plan to use the bulk procurement model to replace government-owned combustion-engine vehicles with electric vehicles [83]. The success of such EV adoption will be predicated on the parallel implementation of policy initiatives to deploy charging infrastructure of appropriate design and scale, to incentivize appropriate business models for vehicle batteries, and by analyzing whether fast charging or battery swapping models are more appropriate for the transportation system [84-86]. 
Second, policies that influence the evolution of a technology often stem from goals beyond the sole objective of technology diffusion. In developing countries, domestic value addition requirements and specific configuration of import duties are often aimed at building domestic industrial capacity while reducing import dependence. For example, in the early phase of the expansion of China's silicon-based photovoltaic manufacturing industry in the 2000 s, there was no strong policy support for domestic photovoltaic adoption. China's rise as the top manufacturer and exporter of silicon-based photovoltaic cells and modules was supported by, among other factors, provincial and local-level policies that provided fiscal incentives for the expansion of high-tech export-oriented manufacturing [87], with the goal of building industrial capabilities and economic growth through exports. However, protectionist policies such as domestic value addition requirements can have trade-offs, as seen in the comparison of contemporaneous expansion of wind energy industries in India and China [88]. While India was able create at least one globally competitive private-sector wind turbine exporter by forcing domestic manufacturers to compete with their foreign counterparts, China's protectionist policies resulted in the expansion of domestic turbine manufacturing with sub-optimal quality standards and few exports.

Third, international trends influence the evolution of technology innovation systems especially in rapidly developing countries. Creative national-level policy initiatives do not operate in isolation, and instead their success significantly depends on global technology- and industry-specific trends as well as on technological spillovers or the lack thereof. In India's LED case, the effects of two key global trends are observed. First, it was possible to fulfil the huge demand created for LED bulbs because of the standardization and commoditization of LED chip technology worldwide and the capacity to manufacture LED chips and lamps at scale in China. This was juxtaposed with India's historical absence of a semiconductor fabrication ecosystem which led to various unsuccessful attempts for domestic commercial initiatives, especially given the cost competition with Chinese semiconductor manufacturers and global consolidation of relevant intellectual property. At the same time, while it is possible to import and deploy a compact, mass-produced, relatively reasonably priced, globally traded standardized technology such as LED bulbs and solar photovoltaics, the same does not hold true of other technologies. For e.g., 
scaling the adoption of electric vehicles will necessitate some domestic design and manufacturing given the higher costs, different performance (e.g., travel/driving patterns), and infrastructural constraints (e.g., charging infrastructure, power rating of electricity supply) [8486] in different countries. Instead, a country's capabilities for domestic manufacturing would be subject to its strengths and weaknesses in other related industry sectors and technologies. In India, it was technological spillovers from domestic manufacturing ecosystems for older lighting technologies and other industries that enabled, although at a slower pace than the market growth, the expansion of the domestic manufacturing of optical and mechanical components and lamp assembly. A second effect of the role of global trends in India's LED case is the importance of the subsidiaries of foreign enterprises in lighting products who were the leading suppliers of procured LED bulbs and among the leading brands in the retail market. These multinational enterprises from developed countries played a key role in the technological transition by expanding their $R \& D$ and manufacturing in the domestic emerging economy. This trend is seen more broadly in India and China, where R\&D centers of foreign multinationals are already among the hot spots of innovation [89].

Finally, the absence of strong linkages among various parts of the innovation system - e.g. research ecosystem, manufacturing in industry, and market formation initiatives - reduces the full leverage of a country's technological capabilities. This is especially true for developing countries, where innovation systems are not as mature. For instance, earlier public investments in R\&D in Indian government labs and higher education institutions created the foundation from which SSL-related research on materials, chip fabrication, and packaging could be substantially strengthened in recent years (more than several other OECD countries). However, the interface of research (academia and government labs) with the R\&D and manufacturing side of industry is missing, despite their complementarities, resulting in low domestic value addition and a weaker overall technology innovation system. A contrasting example is Brazil's technology transition in sugarcane ethanol (as a transportation fuel). In the early phase of this transition between 1970 and mid-1980s, the government funding for collaborative R\&D between public-sector research institutions and industry helped speed commercialization of technological advancements in ethanol production [90]. The technological capabilities developed as a result helped the ethanol industry sustain even during the subsequent period of declined government subsidies between 
mid-1980s and 2000 [91]. An important lesson that emerges is that a long-term strategy is necessary - one that focuses on the entire innovation chain, with $\mathrm{R} \& \mathrm{D}$, manufacturing, demandside management, and skill development, and which fosters linkages among various components of the technology system. Consistent coordinated actions are needed that take into account all parts of a technology innovation system, which involve making strategic choices in individual TIS dimensions (e.g. which part of the technology value chain to focus on within the supply side dimension to build industrial capabilities).

Moving forward, as South-South and North-South engagements on technology innovation, transfer, and deployment increase, a focus on the long-term and strategic linkages among various components of the innovation system will be important to lock-in low-carbon growth in countries' development pathways. Further study of how low-carbon energy technologies, like solar photovoltaic or electric vehicles, could be developed and deployed at scale in developing countries, and understanding their links between national-level policies and international technology trends and supply chains would be immensely impactful in climate mitigation and sustainable development efforts. The limited literature from developing countries in spite of their large potential for low-carbon transitions makes such further research crucial in the near term.

\section{Supplementary information}

\section{S1. An indicative list of key interviewees (anonymized)}

- Business strategy head, Luminous Power Technologies Pvt. Ltd.; Indian company in LED lighting products and other small electrical appliances and components.

- CEO, Philips Lighting Solutions, South Asia; Indian subsidiary of a foreign multinational company in lighting products

- CEO, Svarochi company; Indian company in smart LED lighting products

- Distinguished Member of the technical staff of Sandia National Laboratory, USA; a national lab in the US

- Former head of India's Bureau of Energy Efficiency, Ministry of Power, Government of India; the government body instrumental in setting up the LED policy

- Former head of the Department of Scientific and Industrial Research (DSIR) SSL R\&D program; a national lab in India

- Former senior management, Bajaj Electronics; Indian lighting company 
- Head of Energy Efficiency Services Limited; a public-sector company in the energy efficiency industry and responsible for implementing the government's LED policy

- Managing Director, NTL Electronics India Ltd.; an SSL Systems Design and Manufacturing company

- Past President, the Electric Lamp and Components Manufacturers' Association of India (ELCOMA); Indian lighting industry association

- Professors at the Indian Institute of Technology; the premier engineering and technology higher education institute on India

- Retailers and households who sell/supply and purchase LED bulbs

- Senior researchers at various think-tanks and research groups across India

- Senior scientist at the Materials Research Centre, Indian Institute of Science; a top-tier higher education and research institute in India

\section{S2. An indicative list of key interview themes and questions}

- Global SSL landscape:

- Which are the leading countries in SSL R\&D and manufacturing in different parts of the SSL supply chain?

- How have these capabilities evolved over time?

- Expected future global trends:

○ In what way is the SSL technology expected to evolve in near future?

- What are the main outstanding technical problems and growing research areas?

- In which areas are there opportunities for late-comer countries like India?

- Indian SSL and LED policies:

- Which stakeholders were involved in the design and implementation of the LED policy program?

- What are other SSL-related policy initiatives in India?

- How did the UJALA initiative come into existence?

$\circ$ What were the policy goals?

- How is it being implemented?

- How and why was this specific model chosen?

- Implications of Indian LED policies:

- What have been the implications of UJALA and other policy initiatives for SSL $\mathrm{R} \& \mathrm{D}$, manufacturing, and market penetration in India?

- Is the bulk procurement model sustainable? Why or why not?

- Is this model transferrable to other technologies? Why or why not?

- Indian SSL technical standards:

- How did the Bureau of Indian Standards design technical standards for LED lamps?

- Did stakeholders outside the government, such as industry or research institutions, play a role in designing the standards?

- How are the standards enforced?

- Future expectations and strategy for Indian SSL:

- Going forward, what are the opportunities and challenges for the SSL industry and R\&D and SSL-related policy initiatives in India?

○ What is the future strategy of your organization?

- SSL R\&D: 
- What are the key competency areas and research institutions or companies?

- How have these capabilities evolved?

- SSL industry:

- Within the SSL supply chain, what are the key competency areas of India's SSL manufacturing ecosystem?

- Which are the leading companies and in which part of the SSL supply chain?

- How have these capabilities evolved over time?

- Demand side:

- What are the rates of and reasons behind rapid market penetration?

- What is the quality of the bulb and what are the implications of quality for end users?

\section{References}

[1] Metz B, Davidson OR, Martens J-W, van Rooijen SNM, Van Wie McGrory L. Methodological and technological issues in technology transfer. Cambridge: Intergovernmental Panel on Climate Change; 2002. p. 521-2 \%U http://www.cambridge.org/us/academic/subjects/earth-andenvironmental-science/climatology-and-climate-change/methodological-and-technologicalissues-technology-transfer-special-report-intergovernmental-panel-climatechange? format $=$ HB\&isbn=9780521800822.

[2] United N. Paris Agreement. United Nations \%U https://unfccc.int/sites/default/files/english_paris agreement.pdf; 2015.

[3] Perez C. 11. Capitalism, Technology and a Green Global Golden Age: The Role of History in Helping to Shape the Future. The Political Quarterly. 2016; 86:191-217 \%* (C) The Author 2016. The Political Quarterly (C) The Political Quarterly Publishing Co. Ltd. Published by John Wiley \& Sons Ltd \%U https://onlinelibrary.wiley.com/doi/abs/10.1111/467-923X.12240.

[4] Perez C. Unleashing a golden age after the financial collapse: Drawing lessons from history. Environmental Innovation and Societal Transitions. 2013; 6:9-23 \%U http://www.sciencedirect.com/science/article/pii/S2210422412000743.

[5] Wieczorek AJ. Sustainability transitions in developing countries: Major insights and their implications for research and policy. Environmental Science and Policy. 2018; 84:204-16.

[6] Khosla R, Sagar A, Mathur A. Deploying Low-carbon Technologies in Developing Countries: A view from India's buildings sector. Environmental Policy and Governance. 2017; 27:149-62.

[7] Pueyo A, Mendiluce M, Naranjo MS, Lumbreras J. How to increase technology transfers to developing countries: A synthesis of the evidence. Climate Policy. 2012; 12:320-40.

[8] Yap; Truffer B. A systemic approach to shape selection environments for sustainability transitions: How catch-up countries can endogenize windows of opportunity. Forthcoming in Research Policy journal.

[9] Gosens J, Lu Y. From lagging to leading? Technological innovation systems in emerging economies and the case of Chinese wind power. Energy Policy. 2013; 60:234-50.

[10] Bai X, Dawson RJ, Ürge-Vorsatz D, Delgado GC, Barau AS, Dhakal S, et al. Six research priorities for cities and climate change. Nature. 2018; 555:23 \%* 2018 Nature \%U http://www.nature.com/articles/d41586-018-02409-z.

[11] Berkhout F, Angel D, Wieczorek AJ. Asian development pathways and sustainable sociotechnical regimes. Technological Forecasting and Social Change. 2009; 76:218-28. 
[12] Blum NU, Bening CR, Schmidt TS. An analysis of remote electric mini-grids in Laos using the Technological Innovation Systems approach. Technological Forecasting and Social Change. 2015; 95:218-33. http://www.sciencedirect.com/science/article/pii/S0040162515000189.

[13] Tigabu AD, Berkhout F, van Beukering P. The diffusion of a renewable energy technology and innovation system functioning: Comparing bio-digestion in Kenya and Rwanda. Technological Forecasting and Social Change. 2015; 90:331-45.

[14] Wieczorek AJ. Sustainability transitions in developing countries: Major insights and their implications for research and policy. Environmental Science \& Policy. 2018; 84:204-16. http://www.sciencedirect.com/science/article/pii/S1462901117308092.

[15] ELCOMA. Lighting Industry Data 2018-19. Electric Lamp and Component Manufacturers Association of India (ELCOMA); 2019. http://www.elcomaindia.com/wpcontent/uploads/Lighting-Data-2018-01.05.2019.pdf.

[16] US Department of Energy. Solid State Lighting LED Manufacturing Roundtable Summary. 2011. https://www1.eere.energy.gov/buildings/publications/pdfs/ssl/ssl-led-roundtablereport 03-11.pdf.

[17] Brodrick J. R\&D plan. DOE SSL Program2016. https://www.energy.gov/sites/prod/files/2016/06/f32/ss1 rd-plan \%20jun2016 2.pdf.

[18] SEMI. World LED Epitaxy Capacity Growth (customized dataset produced for this paper). 2018. SEMI website: http://semi.org/en/.

[19] UNESCO Institute for Statistics (UIS). http://data.uis.unesco.org/.

[20] ELCOMA. Lighting Industry in India: Trend 2010-2017. 2017. http://www.elcomaindia.com/wp-content/uploads/Lighting-Industry-India-2017.pdf.

[21] Tsao JY, Coltrin ME, Crawford MH, Simmons JA. Solid-state lighting: an integrated human factors, technology, and economic perspective. Proceedings of the IEEE. 2010; 98:1162-79.

[22] OECD/IEA. Energy Efficiency Market Report. 2016. http://www.iea.org/publications/freepublications/publication/mediumtermenergyefficiency 2016. pdf.

[23] Baumgartner T, Wunderlich F, Jaunich A, Sato T, Bundy G, Grießmann N, et al. Lighting the Way: Perspectives on the Global Lighting Market2012.

[24] Gerke BF, Ngo AT, Alstone AL, Fisseha KS. The evolving price of household LED lamps: Recent trends and historical comparisons for the US market. 2014.

[25] Fu Y. China SSL Technology and Industry Development Strategies. CSA Consulting; 2011. p. Presentation. https://sarienergy.org/oldsite/PageFiles/What_We_Do/activities/Lighting_Transformation_Forum_Jan2011 19 - Yuan Fu.pdf.

[26] OECD/IEA. Energy Technology Perspectives. 2017. https://webstore.iea.org/energytechnology-perspectives-2017.

[27] Weber KM, Truffer B. Moving innovation systems research to the next level: towards an integrative agenda. Oxford Review of Economic Policy. 2017; 33:101-21 \%U https://academic.oup.com/oxrep/article/33/1//2972713.

[28] Bergek A, Jacobsson S, Carlsson B, Lindmark S, Rickne A. Analyzing the functional dynamics of technological innovation systems: A scheme of analysis. Research Policy. 2008; 37:407-29. http://www.sciencedirect.com/science/article/pii/S004873330700248X.

[29] Carlsson B, Stankiewicz R. On the nature, function and composition of technological systems. Journal of evolutionary economics. 1991; 1:93-118. 
[30] Hekkert MP, Suurs RAA, Negro SO, Kuhlmann S, Smits REHM. Functions of innovation systems: A new approach for analysing technological change. Technological Forecasting and $\begin{array}{llll}\text { Social } & \text { Change. 2007; } & \text { 7413-32. }\end{array}$ http://www.sciencedirect.com/science/article/pii/S0040162506000564.

[31] Markard J, Raven R, Truffer B. Sustainability transitions: An emerging field of research and its prospects. Research Policy. 2012; 41:955-67.

http://www.sciencedirect.com/science/article/pii/S004873331200056X.

[32] Markard J, Truffer B. Technological innovation systems and the multi-level perspective: Towards an integrated framework. Research Policy. 2008; 37:596-615. http://www.sciencedirect.com/science/article/pii/S0048733308000164.

[33] van den Bergh JCJM, Truffer B, Kallis G. Environmental innovation and societal transitions: Introduction and overview. Environmental Innovation and Societal Transitions. 2011; 1:1-23 \%U http://www.sciencedirect.com/science/article/pii/S2210422411000219.

[34] Hekkert M, Negro S, Heimeriks G, Harmsen R. Technological innovation system analysis. Technological innovation system analysis,(November). 2011; 16.

[35] Lundvall B-A. National Systems of Innovation: Toward a Theory of Innovation and Interactive Learning. London, New York, Delhi: Anthem Press; 2010.

[36] Malerba F, Nelson RR. Economic development as a learning process: Variation across sectoral systems: Edward Elgar Publishing; 2012.

[37] Truffer B, Murphy JT, Raven R. The geography of sustainability transitions: Contours of an emerging theme. Environmental Innovation and Societal Transitions. 2015; 17:63-72\%U http://www.sciencedirect.com/science/article/pii/S2210422415300058.

[38] Alkemade F, Kleinschmidt C, Hekkert MP. Analysing emerging innovation systems: A functions approach to foresight 2007.

[39] Jacobsson S, Bergek A. Transforming the energy sector: the evolution of technological systems in renewable energy technology. Industrial and corporate change. 2004; 13:815-49.

[40] Johnson A, Jacobsson S. Inducement and blocking mechanisms in the development of a new industry: the case of renewable energy technology in Sweden. Technology and the market: demand, users and innovation2001. p. 89-111.

[41] Dewald U, Truffer B. Market formation in technological innovation systems-diffusion of photovoltaic applications in Germany. Industry and Innovation. 2011; 18:285-300.

[42] Negro SO, Hekkert MP. Explaining the success of emerging technologies by innovation system functioning: the case of biomass digestion in Germany. Technology Analysis \& Strategic Management. 2008; 20:465-82.

[43] Vasseur V, Kamp LM, Negro SO. A comparative analysis of Photovoltaic Technological Innovation Systems including international dimensions: the cases of Japan and The Netherlands. Journal of Cleaner Production. 2013; 48:200-10. http://www.sciencedirect.com/science/article/pii/S095965261300022X.

[44] Markard J, Petersen R. The offshore trend: Structural changes in the wind power sector. Energy Policy. 2009; 37:3545-56.

[45] Huang P, Negro SO, Hekkert MP, Bi K. How China became a leader in solar PV: An innovation system analysis. Renewable and Sustainable Energy Reviews. 2016; 64:777-89.

[46] Ambole A, Musango JK, Buyana K, Ogot M, Anditi C, Mwau B, et al. Mediating household energy transitions through co-design in urban Kenya, Uganda and South Africa. Energy Research \& Social Science. 2019; 55:208-17. 
[47] Lee H, Jung E-Y, Lee J-D. Public-private co-evolution and niche development by technology transfer: a case study of state-led electricity system transition in South Korea. Energy Research \& Social Science. 2019; 49:103-13.

[48] Mah DN-y. Community solar energy initiatives in urban energy transitions: A comparative study of Foshan, China and Seoul, South Korea. Energy Research \& Social Science. 2019; 50:12942.

[49] Geels FW, Schwanen T, Sorrell S, Jenkins K, Sovacool BK. Reducing energy demand through low carbon innovation: A sociotechnical transitions perspective and thirteen research debates. Energy research \& social science. 2018; 40:23-35.

[50] Franco E, Ray S, Ray PK. Patterns of Innovation Practices of Multinational-affiliates in Emerging Economies: Evidences from Brazil and India. World Development. 2011; 39:1249-60.

[51] $\mathrm{He} \mathrm{X,} \mathrm{Mu} \mathrm{Q.} \mathrm{How} \mathrm{Chinese} \mathrm{firms} \mathrm{learn} \mathrm{technology} \mathrm{from} \mathrm{transnational} \mathrm{corporations:} \mathrm{A}$ comparison of the telecommunication and automobile industries. Journal of Asian Economies. 2012; 23:270-87.

[52] Bureau of Indian Standards (BIS). Indian Standard IS 16102-2 (2012): Self - Ballasted LED Lamps for General Lighting Services, Part 2: Performance Requirements. 2012.

[53] Chunekar AM, Sanjana; Kelkar, Mrudula. Understanding the impacts of India's LED bulb programme, "UJALA". 2017. http://www.prayaspune.org/peg/publications/item/download/800 f0b95c623a9c2c6a9c6f64a58d 8d0ale.html.

[54] EESL. India's Ujala Story. Energy Efficiency Services Limited (EESL) \%U https://www.eeslindia.org/writereaddata/Ujala\%20Case\%20study.pdf; 2014.

[55] MoEfcc. India's Intended Nationally Determined Contribution: Working Towards Climate Justice. New Delhi: Ministry of Environment, Forest and Climate Change; 2015. http://www4.unfccc.int/ndcregistry/PublishedDocuments/India\%20First/INDIA\%20INDC\%20T O\%20UNFCCC.pdf.

[56] Sanderson SW, Simons KL. Light emitting diodes and the lighting revolution: The emergence of a solid-state lighting industry. Research Policy. 2014; 43:1730-46. http://www.sciencedirect.com/science/article/pii/S0048733314001322.

[57] DeitY. Electronics and Information Technology, Annual Report. Department of Electronics and Information Technology (DeitY), Ministry of Communications and Information Technology, Government of India; 2015-16. http://meity.gov.in/writereaddata/files/annual-report2015\%E2\%80\%9316.pdf.

[58] ELCINA. Electronic Components, Hardware Market, Manufacturing Ouput Study (ELCOMOS) Including Related Assemblies \& Value Chain in India. 2012. http://meity.gov.in/writereaddata/files/ELCOMOS Report 23412.pdf.

[59] CSIR Developing India's First Indigenously Fabricated LED Chip. EFY Times2010. https://www.icast.org.in/news/2010/apr10/Apr08EFY.pdf.

[60] EESL. Open Tenders for Design, Manufacture, Supply of Self-Ballasted 7W/9W LED bulbs. In: Energy Efficiency Services Limited (EESL) I, editor.Multiple tenders during 2015-2018.

[61] DeitY. Policy for Preference to Domestically Manufactured Electronic Products in Government Procurement (F.No.33(3)/2013-IPHW) - Notification for LED products. In: Department of Electronics and Information Technology (DeitY) of Ministry of Communications and Information Technology GoI, editor.2014. http://meity.gov.in/writereaddata/files/LED\%20Products_22 5 _2014.pdf. 
[62] BIS. Database of Registered Manufacturers. Bureau of Indian Standards (BIS). https://www.crsbis.in/BIS/Lims registration.do?hmode=getLimsData.

[63] India ELaCMAo. EL 1203: SPECIFICATIONS FOR LED SELF BALLASTED LAMPS. 2013.

http://www.elcomaindia.com/wp-

content/uploads/Final_ELCOMAselfballastedlamps_Nov 7 2013.pdf.

[64] Khosla R, Neelanjan Sircar, Bhardwaj A. Energy demand transitions and climate mitigation in low-income urban households in India. Environmental Research Letters. 2019; 14:095008.

[65] Chunekar A, Kulkarni S. Lighting: LED all the way. Prayas (Energy Group). http://www.prayaspune.org/peg/lighting-led-all-the-way.

[66] Negro SO, Alkemade F, Hekkert MP. Why does renewable energy diffuse so slowly? A review of innovation system problems. Renewable and Sustainable Energy Reviews. 2012; 16:3836-46. http://www.sciencedirect.com/science/article/pii/S1364032112002262.

[67] Nemet GF, Husmann D. PV learning curves and cost dynamics. Semiconductors and Semimetals: Elsevier; 2012. p. 85-142.

[68] Philips Lighting India Limited. Annual Report 2016-17. 2016-17.

[69] Batra N, Gulati M, Singh A, Srivastava MB. It's Different: Insights into home energy consumption in India. Proceedings of the 5th ACM Workshop on Embedded Systems For EnergyEfficient Buildings: ACM; 2013. p. 1-8.

[70] DSIR. Report of the Working Group on CSIR: Eleventh Five Year Plan (2007-2012) (Volume I). Department of Scientific and Industrial Research (DSIR), Ministry of Science and Technology, Government of India; 2006. http://www.dsir.gov.in/?textfield=eleventh+five+year+plan\#files/plan_docs/11P_WGR_CSIR.ht m.

[71] MeitY. Skill Development: Electronics System Design and Manufacturing. Ministry of Electronics and Information Technology (MeitY), Government of India. http://esdmskill.deity.gov.in/.

[72] Ministry of Power. Power Saving through Bachat Lamp Yojana. 2011. http://pib.nic.in/newsite/PrintRelease.aspx?relid=77612.

[73] D\&B-India. Study on Innovative Interventions required in Manufacturing Sectors to make them Globally Competitive Presented by Dun \& Bradstreet Information Services India Private Limited (D\&B-India);

2013. http://www.dsir.gov.in/?textfield=task+force\#files/reports/isr1/it_hw_e.html. [74] DeitY. Amendments to Revised Modified Special Incentive Package Scheme (M-SIPS). In: Department of Electronics and Information Technology (DeitY) of Ministry of Communications and Information Technology GoI, editor.2017. http://meity.gov.in/writereaddata/files/msips notification.pdf.

[75] DeitY. Modified Special Incentive Package Scheme (M-SIPS). In: Department of Electronics and Information Technology (DeitY) MoCaIT, Goverment of India, editor.2012. http://meity.gov.in/writereaddata/files/MSIPS\%20Notification.pdf.

[76] DeitY. Electronics and Information Technology, Annual Report. Department of Electronics and Information Technology (DeitY), Ministry of Communications and Information Technology, Government of India; 2017-18. http://meity.gov.in/writereaddata/files/Annual_Report_2017\%E2\%80\%9318.pdf.

[77] MeitY. Annual Report. Ministry of Electronics and Information Technology (MeitY), Government of India; 2018-19. https://meity.gov.in/writereaddata/files/MeiTY_AR_2018-19.pdf. 
[78] India Energy Efficiency Scale-up Program. World Bank; 2018. http://projects.worldbank.org/P162849/?lang=en\&tab=overview.

[79] Gosens J, Lu Y, Coenen L. The role of transnational dimensions in emerging economy 'Technological Innovation Systems' for clean-tech. Journal of Cleaner Production. 2015; 86:37888.

[80] Hansen UE, Nygaard I, Romijn H, Wieczorek A, Kamp LM, Klerkx L. Sustainability transitions in developing countries: Stocktaking, new contributions and a research agenda. Environmental Science \& Policy. 2018; 84:198-203.

[81] Press Information Bureau. Revision of cumulative targets under National Solar Mission from 20,000 MW by 2021-22 to 1,00,000 MW: India surging ahead in the field of Green Energy - 100 GW Solar Scale-Up plan Government of India Cabinet; 2015. https://pib.gov.in/newsite/PrintRelease.aspx?relid=122566.

[82] ASSOCHAM, NEC Technologies India Pvt. Ltd. Electronics \& Electronics Manufacturing in India. 2017. https://in.nec.com/en IN/pdf/-AssochamReport-NTIasKnowledgePartner.pdf.

[83] EESL. Electric https:/eeslindia.org/content/raj/ees1/en/Programmes/ElectricVehicles/e-Vehicles.html.

[84] Zhang X, Rao R, Xie J, Liang Y. The current dilemma and future path of China's electric vehicles. Sustainability. 2014; 6:1567-93.

[85] Rogge M, Wollny S, Sauer D. Fast charging battery buses for the electrification of urban public transport - a feasibility study focusing on charging infrastructure and energy storage requirements. Energies. 2015; 8:4587-606.

[86] Needell ZA, McNerney J, Chang MT, Trancik JE. Potential for widespread electrification of personal vehicle travel in the United States. Nature Energy. 2016; 1:16112.

[87] Binz C, Anadon LD. Unrelated diversification in latecomer contexts: Emergence of the Chinese solar photovoltaics industry. Environmental Innovation and Societal Transitions. 2018; 28:14-34.

[88] Surana K, Anadon LD. Public policy and financial resource mobilization for wind energy in developing countries: A comparison of approaches and outcomes in China and India. Global Environmental Change. 2015; 35:340-59.

[89] Kamat AS, Sagar AD, Narayanamurti V. Study of the Evolution of Transnational R\&D: the Case of US MNEs and India and China (manuscript in preparation).

[90] Meyer D, Mytelka L, Press R, Dall’Oglio EL, de Sousa Jr PT, Grubler A. Brazilian ethanol: Unpacking a success story of energy technology innovation. In: Grubler A, Wilson C, editors. Energy Technology Innovation2014.

[91] Stattman SL, Hospes O, Mol APJ. Governing biofuels in Brazil: A comparison of ethanol and biodiesel policies. Energy Policy. 2013; 61:22-30. 